\title{
Argentina y Chile: percepciones del conflicto de la zona del Beagle
}

\section{PResentación deL TEMA}

"... mientras más se estudia más se hace difícil esperar una solución al diferendo territorial que mantienen la Argentina y Chile en la región austral del Continente. Parece que se necesita de sólo un milagro para solucionarlo y si el Papa no lo hace ¿quién podrá hacerlo?". Declaración de Máximo Gaínza Paz, director del diario La Prensa de Buenos Aires ${ }^{1}$.

La frase antes citada acerca del conflicto de la zona del Beagle constituye un indicio de las dificultades que éste plantea para un análisis desde el ángulo de la teoría de las percepciones. Parece interesante recurrir a este marco conceptual que tiende a valorizar las actuaciones individuales, así como las explicaciones basadas en las imágenes y convicciones de los mismos actores. Es conveniente señalar, no obstante, que existen limitaciones de trasladar un instrumento teórico aplicado a situaciones en que existe un bagaje de conocimientos históricos suficientes para explicar desarrollos de largo alcance en fenómenos completos ${ }^{2}$. Al mismo tiempo, cabe tener en cuenta que se trata de analizar un conflicto territorial específico, lo que plantea a priori algunas interrogantes, en particular acerca de si las percepciones que aparecen son de largo alcance y si gozan de un grado apreciable de estabilidad.

El alcance de las percepciones en este caso preciso puede evaluarse sobre la base dẹ otra constatación y, es de que cualquier análisis supone un conocimiento acabado del sistema de creencias personales de los principales actores. Generalmente, éste se expresa en diversas acciones y decisiones que por su permanencia y constancia en

${ }^{1}$ La Nación, Buenos Aires, 16. 10. 1981.

${ }^{2}$ Ver, en particular, Stanley Hoffman, "Perceptions, Reality and the FrancoAmerican Conflict", y John G. Stoessinger, "China and America: the Burden of Past Misperceptions", en John C. Farrell y Asa P. Smith (eds.) Image and Reality in World Politics, (New York: Columbia University Press, 1968), pp. 57-71 y $72-91$, respectivamente. 
períodos de tiempo extendidos, permiten un análisis de la política exterior de los paises de que se trata y, en general, de las tendencias que imprimen ${ }^{3}$. El hecho de que se destaque actitudes personales puede inducir por otra parte a dejar de lado variables como el sistema internacional o, a menospreciar los cambios en los puestos dentro de un mismo régimen de gobierno.

Teniendo en cuenta estos puntos, es preciso distinguir dos niveles principales de análisis:

- un nivel relativo a lo que constituye la o las percepciones globales acerca de qué cosa es el conflicto y cuál sería una solución adecuada $y$,

- otro nivel constituido por situaciones individuales dentro del conjunto de sucesos cronológicos y que poseen características suficientemente especificas como para permitir el juego de las percepciones de corto plazo.

En ambos niveles se puede apreciar la capacidad orientadora de decisiones que las percepciones pueden ofrecer, así como la influencia de las imágenes históricas en el análisis del comportamiento del otro. Desde este punto de vista, resulta de interés intentar aplicar un concepto teórico como el de percepción, para analizar planteamientos y situaciones que suelen definirse sobre la base de tendencias o realidades objetivas, como son las explicaciones geopolíticas y que tienden a ser excluyentes de otras que pudieren formularse.

En el segundo nivel, por otra parte, aunque los actores tienden a percibirse a sí mismos como poseedores de una gran autonomía en cuanto a las decisiones que pueden adoptar y las actuaciones que pueden desarrollar las interpretaciones deben hacer referencia a la manera cómo se insertan en el nivel más general. Es necesario tener en cuenta, igualmente, que la evaluación de los acontecimientos por los propios actores, dependerá en gran medida de sus propias percepciones, con todas las distorsiones y ajustes necesarios que esto plantea.

Desde el punto de vista del contenido, el análisis está referido a un problema específico dentro de un contexto de relaciones bilaterales, una vez que el asunto del Canal Beagle fue decidido por un fallo arbitral en abril de 19774. Esta decisión significó interpretar el Tratado de Límites de 1881 entre Chile y Argentina y, reconocer que tres islas (Picton, Nueva y Lennox) eran chilenas, al mismo tiempo que señaló la línea del límite en las aguas del canal. Este momento será considerado para iniciar el estudio. Cabe tener pre-

"K. J. Holsti, "National Role Conceptions in the Study of Foreign Policy", International Studies Quaterly, 14, 1970, pp. 232-309.

"Controversia en la Región del Canal Beagle: Laudo Arbitral. Ed. bilingüe, República de Chile, 1977. 
sente que es el cuarto arbitraje en la historia limitrofe entre estos países.

Con estas advertencias preliminares, se intentará un análisis teniendo en cuenta las percepciones e imágenes que influyen, intervienen y/o explican el conflicto situado por los propios actores dentro de un esquema de relaciones esencialmente bilaterales $y$, en que sólo en forma limitada, se inserta explícitamente en un contexto más amplio, regional o mundial. Sin embargo, tanto en la periferia como en la base de algunas tesis, especialmente en las explicaciones del llamado principio bioceánico, la defensa del Atlántico Sur, etc., el conflicto ha sido definido como un elemento clave para entender el rol de cada país en el ámbito regional.

Tomando en cuenta estos supuestos, en particular el que caracteriza el conflicto como uno de carácter territorial, una primera consecuencia que podría inferirse es la de que las percepciones deberían estar desvinculadas de cualesquiera connotación ideológica, ajena al ámbito de la defensa o de la seguridad. Una muestra de esta apreciación es la que formula "Observador" en Argentina", en el sentido de que sería imposible incluir el asunto del Beagle dentro de la guerra ideológica que se libra en el mundo. En cambio, conforme a esta misma postura, ese contexto ideologico sería indispensable para explicar las relaciones solidarias entre Estados Unidos y ese país.

Es así como, por ejemplo, el conflicto es de carácter territorial en cuanto se lo define en torno del supuesto principio AtlánticoPacífico, decisivamente orientado por posiciones geopolíticas y las consecuencias que se extraen de él a la luz del Laudo arbitral de 1977. Chile determina ese año el sistema de líneas de base rectas ${ }^{6}, y$ designa alcaldes del mar. Argentina, mediante la proposición Tor$\mathrm{ti}^{\top}$, propone en 1977, una fórmula combinada de condominio sobre las islas Evout, Barnewveld y Cabo de Hornos, así como una fórmula de delimitación maxítima que significa reconocer 12 millas a ciertas islas y asegurar su presencia soberana. La cuestión abarca, además, según otra explicación de un geopolítico argentino ${ }^{8}$ el control del Estrecho de Magallanes, del Canal de Beagle y del Pasaje Dra. ke, o sea de las tres vías de interconexión oceánica, en las que estarían implicados los criterios geoestratégicos de Chile y, por supuesto, la proyección de ambos países hacia la Antártica.

${ }^{5}$ La Prensa, Buenos Aires, 6. 11. 1981. El comentario se refiere a la visita a EE.uv, del General Galtieri, Comandante en Jefe del Ejército en esa época.

${ }^{\circ}$ Decreto 416, 14. 7. 1977, publicado en Diario Oficial, 15. 7. 1977.

"Propuesta de un Tratado Complementario de Límites", 4. 12. 1977, publicada en El Mercurio, Santiago, 12. 1. 1978, pp. Al-10.

${ }^{8}$ Osiris Villegas, El Conflicto con Chile en la Región Austral, $2^{\text {a }}$ Ed. (Buenos Aires: Pleamar, 1978), pp. 74-76. Osiris Villegas encabezó por Argentina las conversaciones con Chile inmediatamente después de emitido el Laudo Arbitral en 1977. 
Todas estas tesis y planteamientos importan una razón estratégica que incluye dentro del concepto de lo territorial, una preocupación constante por las comunicaciones en el área.

Estas definiciones plantean interesantes elementos a considerar, en el sentido de que ellas pueden conllevar o incidir en la manera cómo dentro de cada país se supone que debería manejarse el asunto y por quiénes debería hacerse.

Uno de los problemas que ha debido ser abordado en este estudio ha sido, en consecuencia, la selección de las explicaciones e imágenes, lo que ha implicado a su vez, una selección de los sujetos envueltos, así como de criterios para determinar el grado y los niveles en los que debe situárselos. Por tratarse de un conflicto en evolución, respecto del cual los intercambios oficiales gozan de un alto grado de privacidad y secreto, se ha tenido fundamentalmente en cuenta la élite política y de opinión conformada por negociadores y ex negociadores, miembros de la Iglesia Católica, oficiales de las Fuerzas Armadas, representantes de' partidos políticos, intelectuales, comentaristas de prensa, etc., que han manifestado su opinión con regularidad y que to han hecho no estando oficialmente obligados a ello. No obstante, estos elementos no pueden ser considerados en forma aislada de los acontecimientos mismos y de las decisiones que se adoptan, de manera de establecer la relación entre percepciones y sucesos, que conduzca en último término a probar la capacidad prescriptiva y predictiva de este marco teórico.

\section{EL CONFIICTO, LOS DIVERSOS GRADOS. DE HOSTIIIDAD $Y$ SU DESARROLLO EN EL TIEMPO}

Con el objeto de orientar el examen, debe tenerse en cuenta que desde el punto de vista del desarrollo en el tiempo, el conflicto presenta las siguientes secuencias:

- Laudo arbitral es comunicado a ambos países. 2. 5. 1977.

- Argentina declara unilateralmente la nulidad del Laudo. 25. 1. 1978. Rodea este acto, una serie de encuentros de alto nivel que culminan con el Acta de Puerto Montt, 20. 2. 1978.

- Ghile y Argentina solicitan al Papa su mediación en el conflicto y se comprometen a no recurrix a la fuerza. 8. 1. 1979.

- Orientaciones de Juan Pablo rr. Octubre y noviembre de 1980.

- La propuesta papal es entregada a los Cancilleres de Chile y Argentina. 12. 12. 1980.

- Chile responde a la propuesta papal. Enero, 1981.

- Argentina responde solicitando precisiones y alcances a la propuesta papal. Marzo, 1981.

- Iniciativas del Canciller argentino Oscar Camilión ante el Vati- 
cano y publicación en Argentina de la supuesta propuesta papal. Agosto y septiembre de 1981.

- Argentina denuncia el Tratado General sobre solución judicial de controversias (Gobierno del General Leopoldo Galtieri). 21. 1. 1982.

- Exhortación del Papa Juan Pablo II a ambos Gobiernos. 23. 4. 1982.

- Acuerdos de ambos gobiernos para prorrogar el Tratado General sobre solución judicial de controversias de 1972 hasta que se celebre el Tratado final propuesto por el Mediador para la solución completa y definitiva del diferendo o, en su defecto, hasta pasados seis meses de la fecha en que el Papa se vea en la necesidad de declarar finalizada su mediación. Chile se compromete a no hacer uso de los derechos que emanan del Tratado sino en el caso de la prórroga antedicha y, sólo en relación con el diferendo específico. 15. 9. 1982.

Dentro de este cuadro simplemente indicativo, el conflicto es definido en primer término como una consecuencia del fallo arbitral. La declaración oficial de la Cancillería argentina señaló en 1977 "...En la consideración del Laudo, el Gobierno argentino si bien tiene presente la tradición de nuestra política exterior de cumplir con los compromisos internacionales contraídos en nombre de la República por los Gobiernos sucesivos, al mismo tiempo mantiene el principio de que ningún compromiso obliga a cumplir aquello que afecte intereses vitales de la nación o que perjudique derechos de soberanía que no hayan sido expresamente sometidos a la decisión de un árbitro por ambas partes"9.

Se plantea así un área de conflicto delimitada por los intereses vitales y el conjunto de creencias que los fundamenta. Aunque expresada en lenguaje jurídico, la declaración de nulidad del Laudo arbitral, 25. 1. 1978, leída por el Canciller Montes, de Argentina, apunta a precisar una definición de los intereses afectados presuntamente por esa decisión: "Es la reacción necesaria ante un Laudo que prescinde de un criterio sustancial de delimitación de jurisdicciones entre ambos Estados, como lo es el principio Atlántico-Pacífico; ante un Laudo que se ha basado en la atribución a Argentina de una posición en la cuestión esencial de la delimitación del Canal Beagle no sustentada por nuestro país y que ha asignado a un Tratado, el de 1881, el alcance de una transacción que le habría atribuido la Patagonia, como si sus derechos históricos sobre ella pudieran haber sido antes seriamente cuestionados"10.

-El Mercurio, Santiago, 3. 5. 1977.

Ior'Documento 1"', en O. Villegas. La Propuesta Pontificia y el Espacio $\mathrm{Na}$ cional Comprometido (Buenos Aires: Pleamar, 1982)., p. 104. 
Estos elementos, considerados en conjunto con lo que puede definirse como una especial visión acerca de lo que Chile debería percibir como la perspectiva histórica más adecuada para relacionarse con Argentina, configuran un enfoque amplio sobre el tema. "Si Chile -expresa un comentario- para discutir las cuestiones limítrofes de cuya solución responsable depende el desarrollo, la tranquilidad y la concreción de los proyectos de integración de ambos países, se atiene, exclusivamente, a la aplicación de criterios interpretativos o mecanismos geométricos, para la traza del límite, sin duda alguna habrá perdido la perspectiva histórica"11.

Con las diferencias propias a los particulares planteamientos dentro de cada país, al nivel de las definiciones más amplias se presenta una interesante simetría, que se englobaría dentro de un marco geopolítico, pero que no cubre los enfoques especialmente diferentes en cuanto al rol del derecho internacional y acerca de los métodos para encarar la controversia.

A este respecto, cabe considerar otro esquema de análisis que sugiere un concepto distinto acerca de lo que constituye el conflicto, en el extremo opuesto a lo antes explicado. Se trata de la posibilidad de enmarcar el conflicto dentro del derecho internacional, lo que a su vez tiene dos connotaciones principales, una relativa a lo que es susceptible de discusión por ambos países y otra, sobre el uso de la vía judicial para que un juez evalúe los argumentos que se le presenten ${ }^{12}$.

Una tercera posibilidad es la que surge de introducir en la definición misma del conflicto la cuestión de la amenaza o del uso de la fuerza para dirimirlo, lo que también puede analizarse desde la perspectiva de las percepciones. En cualesquiera de estos casos, la aproximación dominante es la de que el uso de la fuerza es un recurso subsidiario, susceptible de ser utilizado o que sirve para avalar las exigencias más extremas. Fue el caso a fines de 1977-7813,

${ }^{12}$ Rodolfo Federico Huáscar, Glarin, Buenos Aires, 21. 8. 1977.

${ }^{12 *}$ Chile y Argentina, unidos por múltiples lazos fraternos, cuyo común destino es un imperativo histórico, iniciaron conversaciones sobre delimitación marítima en la zona en que sus fronteras se tocan. No se trata como se lee en cierta prensa argentina, de que frente a una cuestión de orden geo-político, nuevamente se esgrime el principio jurfdico, considerado como inatacable (el recurso a la Corte Internacional de Justicia, de acuerdo con el Tratado General sobre Solución Judicial de Controversias de 1972). "Los Estados, como los hombres, se relacionan en el marco del Derecho, sin Derecho no puede existir el ordenamiento interno $\mathrm{ni}$ el internacional, que permite a los pueblos desenvolverse pacificamente en procura del bienestar de todos". Helmuth Brunner. "Geopolftica versus Derecho". El Mercurio: Santiago, 24. 9. 1977, p. 31. Similares planteamientos hicieron algunos juristas y ex diplomáticos argentinos después de emitido el Laudo Axbitral, en el sentido de que debía acatarse la decisión del árbitro.

${ }^{13}$ Un ejemplo de percepción extrema se da en el siguiente comentario: "... el Gobierno (argentino) no debió creer en la guerra y, si creyó en ella, no debió 
con ciertas reiteraciones en episodios ocurridos durante todo el transcurso de la mediación ${ }^{14}$. Desde la prensa chilena no han sido escasos los análisis que han llamado la atención sobre lo que han denominado la creación de un clima de hostilidad hacia Chile que también se enmarcan dentro de este contexto ${ }^{15}$. Un análisis reciente en Chile acerca del gasto en armamentos de Argentina en el año 1982 (4.000 millones de dólares) explica su origen en dos amenazas, una de las cuales sería desde 1978 el fantasma de la guerra con Chile 16 .

Hasta los acuerdos de Montevideo de enero de 197917, en que el cuadro presenta los elementos conflictivos antes señalados, la relación se caracteriza por un desacuerdo acerca de lo que es negociable, así como por la búsqueda de un entendimiento de alto nivel. Dentro de ése, el período caracterizado por la presentación ide planteamientos en pugna y de oposiciones básicas culminaría con el Acta de Puerto Montt, suscrita por ambos Presidentes, el 20 de febrero de 1978.

Sin duda, en las diversas misiones que funcionaron en ambos países (Comisión Villegas/Phillipi; Misión Torti (Argentina); Misión Montes (Argentina); Misión Toro (Chile); Misión Contreras (Chile), encuentro presidencial de Plumerillo, etc.), los gobiernos y jefes

haberle temido; no pudo tampoco haberle temido, porque debía estar, y estaba, preparado para hacerla.

De ahi que hayan parecido y parezcan aún incomprensibles, desde un punto de vista argentino, los acontecimientos y negociaciones de ese mes de diciembre de 1978, salvo como exaltación pasajera de la imaginación como consecuencia de los infernales calores...". R. A. Paz, El Gonflicto Pendiente: El Beagle $y$ el Cabo de Hornos. (Buenos Aires. Edit. Universitaria de Buenos Aires, 1980), p. 320. El autor cita declaraciones de autoridades de ese país en que las sugerencias a un posible uso de la fuerza son explicitas, entre otras el discurso del General Albano Harguindeguy, en Mendoza: "A quienes dicen por la razón o la fuerza $\circ$ por la fuerza, les decimos por la razón antes que por la fuerza, pero si así no fuera, el más fuerte y poderoso impondrá la fuerza de su voluntad". Tomado de revista Redacción, en Ibid, p. 322, nota 94.

${ }^{14}$ Las operaciones de la flota de guerra argentina en el Atlántico Sur a fines de 1977 y comienzos de 1978 se enmarcarían dentro de este cuadro. En febrero de 1978, Ia prensa informa de maniobras del Ejército argentino en provincias fronterizas con Chile a lo largo de la cordillera de los Andes. El Mercurio, Santiago, 2. 2. 1978, pp. Al y 10:

Desde fines de abril de 1981 a junio de ese año, existió una gran tensión entre ambos pafses, expresada en cierre de fronteras terrestres por el Gobierno argentino, después que Chile detuvo a dos oficiales argentinos en territorio chiIeno, acusándolos de espionaje. En esa época, algunos técnicos, civiles y oficiales del Ejército chileno se encontraban detenidos en Argentina, acusados a su vez de actividades de espionaje.

10Por ejemplo "Distensión Chileno-Argentina", El Mercurio, Santiago, 4. 3. 1978 , p. A3.

${ }_{10}$ "Armamentismo Argentino", El Mercurio, Santiago, 2. 3. 1982, p. A3.

${ }^{17}$ L'Osservatore Romano, edición semanal, 14. 1. 1979, p. 4. 
militares estuvieron en situación de conocer exhaustivamente las posiciones y planteamientos del otro. De este modo, desde el punto de vista teórico, lo relevante sería examinar la validez anticipatoria que las percepciones tienen sobre las opiniones y análisis que forman parte de las decisiones gubernamentales.

En este sentido, considerando sólo la situación hasta los acuerdos de Montevideo de 1979, un primer punto que parece apropiado para introducir el concepto de percepción es la determinación del alcance y límites de la oposición argentina al Laudo arbitral. Declaraciones relativas a que ese país "no tiene otro medio que rechazar el Laudo o impedir por todos los medios que el Gobierno chileno extienda sus pretensiones más allá del Cabo de Hornos, hacia el Atlántico"18 o, lo que expresa el ex Presidente Levingston a favor de la tesis de que sólo mediante esa medida "la integridad de la nación podrá ser preservada, cualesquiera que sea el precio y ésta es una obligación nacional no negociable"19, son signos importantes que anticipan la decisión. Pero la intensidad de los intercambios de alto nivel que la preceden, en los cuales predomina lo que se ha llamado la diplomacia castrense, pareciera indicar que las percepciones en este caso, fundamentalmente desde el lado chileno, estimaban que las alternativas podían ser distintas ${ }^{20}$.

En general, los puntos de encuentro de las percepciones por ambos lados son escasos $y$, éstas se caracterizan por su incompatibilidad. Por el lado argentino, se acentúan los efectos adversos del fallo arbitral debido a que éste reconocería u otorgaría el carácter bioceánico a Chile, y, por otra parte, opera la "visión" según la cual "Ghile no tiene conflicto alguno con sus vecinos, ni tampoco con Argentina. La tarea de delimitar espacios marítimos, plataforma continental y zonas económicas entre ambos países es impuesta por el moderno Derecho Internacional que, en conformidad a sus normas, ha de encontrar solución por la vía de los acuerdos directos o en su defecto, por decisión judicial. Es lo que ordena el Derecho de Gentes y nadie podrá imputar a Chile espíritu expansionista por el hecho de hacer valer sus justos derechos"21.

Estas explicaciones pueden estimarse equivalentes a descripciones de la controversia, pero no reflejan cabalmente cuál es el estado

${ }^{18} \mathrm{La}$ Opinión, Buenos Aires, 7. 1. 1978.

${ }^{18}$ El Mercutrio, Santiago, 8. 1. 1978.

${ }^{20} \mathrm{La}$ hipótesis que puede plantearse es la de que conforme a los antecedentes existentes, era posible anticipar la declaración de nulidad por parte de Argentina. Puede estimarse que, no obstante eso, opera una percepción de corto plazo desde Chile, que estaría corroborada por la visita de un enviado especial del Presidente Pinochet (General Manuel Contreras), portador de una carta al Presidente Videla, la que fue examinada por el Comité Militar Argentino. Cable UPI, Buenos Aires, El Mercurio, Santiago, 14. 1. 1978, p. A.12. No 59 .

21 Julio Phillipi. Declaraciones a La Semana, Buenos Aires, diciembre, 1977, 
exacto de la situación en la fecha en que se emiten, así como cuál podia ser el curso probable de los acontecimientos en los meses futuros.

\section{II}

Considerando el conflicto en su conjunto hasta la época de preparación de este trabajo e introduciendo un elemento adicional, la mediación papal (1979 en adelante), esos elementos preliminares pueden ser desarrollados en torno de las siguientes explicaciones globales que se supone, corresponden a percepciones claves.

\section{La explicación de la geopolitica}

En cuanto a Argentina, una concepción que puede ser tanto de carácter histórico como coyuntural, señala que "las intenciones de Chile" son claras y nunca las ha ocultado. "La usurpación que hace de las islas Picton, Lennox y Nueva desde fines del siglo pasado persigue como su único objeto: salir al Océano Atlántico para convertirse en potencia bioceánica" 22 .

Se denomina en ese enfoque como geopolítica de Chile en el área del Laudo arbitral, lo que se expresaría en las siguientes proposiciones: a) la convicción en ese país de que sufre un encierro geopolítico y la necesidad que siente de quebrarlo, to que se traducirfa en dos constantes de su conducta: el control y la hegemonía en el Océano Pacífico Sudamericano y, una tendencia expansionista que reconocería dos variantes, en el Norte, a expensas de Perú y Bolivia y, en el Sur, que sólo podría concretarse a expensas de Argentina; b) dentro de ese esquema, la vinculación Chileno-Argentina, se daría esencialmente en torno al principio denominado "bioceánico"23.

Las tendencias expansionistas de Chile y el acceso a los recursos del mar en espacios propios ocupan un lugar primordial en ese enfoque 24 .

Asimismo, la percepción geopolíticamente orientada en Chile acerca de los objetivos argentinos se fundamenta en el interés que éstos demuestran en el avance hacia el Pacífico, de manera que el país podría quedar cortado al Sur de Puerto Montt ${ }^{25}$. La crisis per-

2ax"Exhortación" del Almirante (A) Isaac F. Rojas en La Argentina en el Beagle y Atlántico Sur, Isaac Rojas (ed.), (Buenos Aires: Nemont Ediciones, 1978), página 229.

${ }^{2}$ Juan E. Guglialmelli, General de División (R), "El Area Meridional del Atlántico Sur Occidental, la Geopolítica de Chile y el Laudo del Beagle", Estrategia, 48, 1977, pp. 10-16.

${ }^{24}$ Jorge Fraga, "EI Mar en la Geopolitica Argentina", Revista de la Escuela de Guerra Naval, 1979, 11/12, pp. 25-47.

${ }^{2} N$. T. Pittman, "Algunas Tendencias Geopolfticas Especificas en los Países 
manente del Beagle permitiría agudizar esta percepción: "Argentina, sin duda, está diseñando su expansión al Pacífico a costa de la infraestructura vial y portuaria chilena, para lo cual la integración constituye el único camino"26.

Antes de la declaración de nulidad del Laudo (enero de 1978), en Argentina se sostiene conforme a estas premisas, el rechazo total a lo decidido por el árbitro. Después de esa declaración de nulidad. $y$, estando en curso el procedimiento acordado en Puerto Montt (febrero de 1978), de comisiones chileno-argentinas, se objeta cualquier intento o principio de solución que implique el reconocimiento de soberanía de Chile sobre Picton, Nueva y Lennox, desechando por supuesto todo lo que implique reconocer validez al Laudo.

Esta tendencia se expresa en el movimiento pro impugnación del Laudo arbitral del Beagle, convertido en el Movimiento Reafirmación de Soberanía Argentina, Picton, Lennox y Nueva y demás islas del Atlántico Sur $^{27}$.

Además de que estas apreciaciones contienen en forma explícita la posibilidad del uso de la fuerza ${ }^{28}$, ellas conllevan una doble crítica a la conducción diplomática del tema, dirigida a los encargados de las conversaciones y negociaciones con Chile (Fuerzas Armadas y Cancillería) en cualquier época del pasado $y$, otra que se hace cada vez más abiertamente después de la declaración de nulidad, dirigida al Gobierno chileno, a quien se le atribuye tácticas dilatorias en este asunto.

Por una parte, se explica que el país (Ghile) adheriría al sistema de reuniones presidenciales, a gestiones inconducentes de representantes militares y por otra parte, no adoptaría ninguna actitud que signifique madificar sus planteamientos respecto de Ia soberanía en las islas australes. Estas percepciones tienen, en consecuencia, un aspecto cognitivo puro acerca de la actitud del otro, que es esencial para las consecuencias que se infieren en cuanto al curso de las futuras relaciones.

En lo que el capitán de navio Francisco Ghisolfo Araya, de la Marina Chilena expone en $1979^{29}$, se incorporan elementos de la misma naturaleza, dándose un alto grado de congruencia entre lo

del ABG. Nuevas aplicaciones de la Ley de las Areas Valiosas", Revista de Ciencia Politica, 1979, 1/2, p. 53.

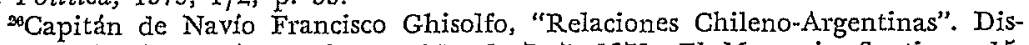
curso en la Academia de Guerra Naval, 7. 7. 1979. El Mercurio, Santiago, I5. 7. 1979 , p. 4 .

${ }^{2 \pi}$ Los adherentes a estos movimientos animan las Jornadas del Canal de Beagle y Atlántico Sur.

2sDeclaración del Movimiento pro-impugnación del Laudo arbitral del Beagle, La Argentina en el Beagle y Atlántico Sur, op. cit., pp. 234-5. Firmaron 18 personas, entre ellas, Isaac Rojas y Alfredo Rizzo Romano.

${ }^{20}$ Siendo Director de la Academia de Guerra Naval. 
que constituye la imagen histórica sobre las relaciones con Argentina y la situación específica que se vive en ese momento.

- Respecto del primer elemento, señala que "aparece así, nuestro país, como la principal víctima de sus apetitos y la historia no hace más que confirmarlo: la pérdida de la Patagonia, las cesiones en la Isla Grande de Tierra del Fuego, la Puna de Atacama y las entregas producidas en los valles cordilleranos constituyeron sin duda algunos acuerdos pacíficos, pero que han dejado grandes extensiones que fueron nuestras en manos de Argentina, las que suman ya 1.264.260 kilómetros cuadrados, cancelados en cinco cuotas como precio de la paz, como en forma tan gráfica como irónica lo expresa el escritor ya citado en su libro El Precio de la Paz Chileno-Argentina"30.

Una proyección más amplia de lo que se denominaría una autopercepción, se manifiesta en otra intervención del mismo actor ${ }^{31}$ tendiente a explicar la proyección oceánica del país en la defensa del Atlántico Sur, en un cuadrilátero formado por Chile con Punta Arenas, el Beagle, la Antártica; Gran Bretaña con las islas Falkland; la Unión Sudafricana y el Brasil como la base de sustentación de esa defensa.

Aunque no son tan abundantes como en Argentina los enfoques que abiertamente explican la perspectiva chilena conforme a conceptos geopolíticos, Chile geopolitico. Presente y futuro $0^{32}$, incorpora también un conjunto considerable de elementos históricos para fundamentar la estabilidad de la imagen que se posee del otro: "Si nos orientamos bajo estas concepciones geopolíticas, podemos darnos cuenta del error descomunal de quienes, en nuestras discusiones con Argentina el siglo pasado, acerca del dominio de la Patagonia, debilitaron y desorientaron muchas veces la acción diplomática y las medidas de seguridad del territorio, por el menosprecio que hicieron de este vasto espacio"33. Esta tendencia no habría sido superada $y$, en cuanto al comportamiento argentino, éste correspondería al de una potencia revisionista, mientras el de Chile favorecería el statu-quo.

La geopolítica argentina es entonces percibida como expansionista, resultado de una frustración que agobiaría a los autores que se

"Relaciones Chileno-Argentinas". Op. cit., p. D4. Se cita al historiador Oscar Espinosa Moraga.

"Tesis sostenida al condecorarse al Contralmirante sudafricano, Martinius A. Bekker, Director General de los Servicios de las Fuerzas Armadas de Sudáfrica, 19. 4. 1981, El Mercurio, Santiago, 23. 5. 1981, p. A20. EI Gobierno chileno no reconoció carácter oficial a esta declaración.

${ }^{2}$ Oscar Buzeta, Vicealmirante (R), Santiago, crsec.

Ibid, p. 261. 
inspiran en ella $a^{34}$, respecto de un país que aspira a ser potencia hegemónica regional.

Ese rol de liderazgo en el Cono Sur que se autoasignaría Argentina $y$, que es percibido como una pretensión hegemónica en Chile, no se presenta únicamente en el conflicto del Beagle, sino que desde años antes aparecería incorporado en los estudios geopolíticos internos ${ }^{35}$.

Analizando el conflicto en esta perspectiva, el grado de discrepancias entre las posiciones de los dos países es muy alto. Tras ellas se observa una legitimación del uso de la fuerza por parte de un sector belicista que es percibida en Chile como un elemento real, mas parte de un falso dilema presente en las negociaciones entre ambos países ${ }^{36}$. En lo inmediato, la disparidad acerca de lo que debe ser la conducción del conflicto no puede ser mayor, pero el resultado es de que ninguna de las dos partes logra imponer totalmente su visión, en un caso, el recurso judicial ante la Corte Internacional de Justicia (Chile) y en el otro, un acuerdo que anule los efectos del Laudo arbitral (Argentina).

La percepción geopolítica de este último país experimenta variaciones en el curso de la mediación papal, pero no de contenido sino de acentuación de críticas a la gestión del mediador y, a los planteamientos y respuestas del propio Gobierno argentino ${ }^{37}$.

En esa perspectiva y, en especial, después que el Papa formula su propuesta a los gobiernos (diciembre de 1980), las tesis expuestas no sufren modificaciones de consideración, indicándose que además de una inadecuada defensa de los objetivos argentinos, existiría una falta grave de correspondencia entre las posibilidades de tener éxito que la Junta Militar estima tener, consecuencia de la falsa imagen que le proyectan sus representantes ante el Papa y la falta de un planteamiento claro ante el mediador ${ }^{38}$. En estos términos, en el aspecto coyuntural representado por la propuesta y su recepción por Argentina, este sector estima que una correcta apreciación de los

sirbid, pp. 271-2.

${ }^{\star}$ General Augusto Pinochet Ugarte, Geopolitica. (Santiago: Andrés Bello, 1974), pp. 63-64.

s"Imponer el derecho mediante el diálogo de Ias armas", señaló Juan E. Guglialmelli, General de División $(R)$ en 1978, después del Acta de Puerto Montt. "Cuestión del Beagle. Negociación Directa o Diálogo de Armas", Estrategia, 49/ 50, 1977-1978, p. 22. Contra esta hipótesis véase "Amenaza fuera de lugar", El Mercurio, Santiago, 20. 5. 1978 p. A3.

${ }^{3}$ Tsaac Rojas. Conferencia en Centro de Oficiales de las Fuerzas Armadas, La Nueva Provincia, Bahfa Blanca, 18. 10. 1981.

${ }^{3}$ Alberto R. Assef, Planteo, Buenos Aires, septiembre, 1981. Una anticipación de este análisis en Isaac F. Rojas y Arturo L. Medrano, Argentina en el Atlántico y Chile en el Pacifico, 2a ed. (Buenos Aires: Nemont Ediciones, 1979), pp. 5-23. Igualmente, en el conjunto de artículos incluidos en el libro Una Geopolítica Nacional Desintegrante, de Isaac F. Rojas (ed.), (Buenos Aires: Nemont Ediciones, 1980). 
acontecimientos debe incluir la crítica a la diplomacia ante El Vaticano. En último caso, estas explicaciones no dejan de tener interés en la medida en que sirvan de freno o garantía para cualquier actitud posterior que busque eximirse de responsabilidad frente al propio país $y$, en ese sentido, es un indirecto apoyo al Gobiemo para que mantenga las cosas al nivel de indecisión en que las tiene.

Sin discrepar fundamentalmente de estas tesis, la imagen de que el país (Argentina) pasa del desastre a la "recuperación"39, explica la actitud de la Junta Militar desde el Laudo arbitral hasta sus vacilaciones al conocer la propuesta papal. Este enfoque implica además, que la respuesta que cabe es el rechazo a lo propuesto. Además de explotar en Io inmediato la idea de claudicación, se rechaza el concepto de tutela de la diplomacia del Vaticano en todo el ámbito de la relación con Chile ${ }^{40}$. Otra apreciación señala, en junio de 1981, que siendo la cuestión austral de primera importancia "Ia opinión pública sigue preguntándose infructuosamente qué es lo que se halla en juego en el proceso de la mediación papal, qué es lo que persigue la Argentina, qué es lo que defiende, qué es lo que discute"

En su relación global con Chile estas explicaciones utilizan la imagen del histórico desequilibrio diplomático favorable a Chile ${ }^{42}$, mientras que en proceso de la mediación ese país tiene la iniciativa a nivel internacional. Chile pretendería formar parte de la defensa y seguridad estratégica del Attántico Sur, lo que se habría hecho presente a Estados Unidos, agitando además la idea de la presencia rusa en Argentina. Existen planteamientos que cuestionan al mismo tiempo los acuerdos de integración que surgen del Grupo Empresarial Interregional Centro Este Sudamericano (GEIGOS), por tender a realizar los objetivos políticos permanentes de Chile y contribuir a desmembrar Argentina ${ }^{43}$.

En la perspectiva geoestratégica argentina, la propuesta papal y antes el Laudo, no son aceptables porque implican la pérdida de territorios que se consideran propios $y$ acarrean el debilitamiento argentino en el Atlántico. Ambos instrumentos -se advierte- (Lau-

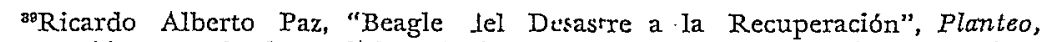
Buenos Aires, septiembre, 1979. Coincide en el rechazo el ex Presidente Levington. Conferencia ante el Círculo de Estudios del Movimiento Humanista Argentino. La Prensa, Buenos Aires, 7. 11. 1981.

${ }^{\circ}$ Ricardo Alberto Paz, "Antártica, el Beagle $y$ las islas Malvinas. Una trilogia de Imprecisiones Diplomáticas", El Sureño, San Rafael, 23. 7. I982.

"Manfred, Schönfeld, La Prensa, Buenos Aires, 16. 4. 1981.

t2"Nuestra República no ha logrado romper con el fatalismo histórico que la rodea, cada vez que debió ventilar cuestiones de límites con sus vecinos, el acuerdo se ha logrado invariable a costa de desmembraciones de territorio argentino". Ernesto J. Fitte, Los Limites con Chile, (Buenos Aires: Plus Ultra, 1978), p. 8.

"'Féctor Sauret, "Area de Capricornio. Fronteras y Neocolonialismo", Estrategia. No 57, PP. 55-86. 
do y propuesta) introducen institucionalmente a Chile en una zona de conflicto.

Al mismo tiempo, se percibe una errónea orientación geopolítica en Chile, al intentar este país poner un pie en una zona atlántica para ofrecer a potencias extranjeras la posibilidad de desarrollar una estructura defensiva en el Atlántico Sur sin contar con Argentina ${ }^{44}$. Desde este punto de vista, Chile tendría una equivocada percepción al disminuir la importancia de Argentina como país atlántico, lo que significa menospreciar la actitud beligerante que ese país puede asumir en el futuro conforme a esta explicación. El pacifismo, que se expresa en el entendimiento con Chile, no debería confundirse con indecisión.

\section{El dilema ético-politico y la propuesta papal}

Dentro del panorama que presenta el conflicto desde el inicio de la mediación $y$, en especial, una vez conocida la propuesta papal (diciembre de 1980), el análisis admite la introducción de otro elemento que está configurado por la adhesión a ciertos valores, la defensa de la soberanía nacional y el respeto al Papa. Se sitúa la propuesta papal en el terreno moral o en el político conforme a las distintas apreciaciones, condicionadas en gran parte por las posiciones geoestratégicas que se sustentan. En este contexto, el juego de los actores políticos y sociales internos es más amplio e intenso.

Esta percepción acerca del proceso de mediación opera principalmente en Argentina y tiende a demistificar los alcances de la negociación, estableciendo una distancia con la Iglesia Católica (jerarquía interna, Vaticano, y sus representantes), así como con lo que se supone es la actitud de la Diplomacia argentina. Contrasta al mismo tiempo esta posición con la que asumen miembros de la jerarquía católica argentina en cuanto al deber de apoyar las gestiones de Juan Pablo $\mathrm{II}^{45}$. Estas diferentes tendencias perduran a lo largo del curso de la mediación en un debate interno, en el cual figura además la proposición de someter cualquier acuerdo definitivo a Ia aprobación del futuro Congreso ${ }^{40}$.

Las opiniones de miembros del clero en sentido favorable a la

\footnotetext{
*Declaraciones de J. Iglesias Rouco, El Mercurio, Santiago, 22. 4. 1982, p. c2. Véase en relación con lo expresado nota 32 supra.

«3"A Dos Aguas No", Somos, Buenos Aires, 11. 12. 1981, p. 2. Aquí se ilustra acerca de las divergencias que traslucen los comentarios de un sacerdote de Rosario, contrario a la campaña de recolección de firmas "por una mediación que podrfa ser perjudicial para la nación". Esta campaña se desarrolló en forma paralela en las dos partes a fines de 1981 .

${ }^{16} \mathrm{El}$ General $(R)$ Osiris Villegas defiende la opción de no mezclar la Iglesia con decisiones del poder político $y$, por último, recurrir al Congreso Nacional, La Prensa, Buenos Aires, 17. 11. 1981. Igual posición en La Propuesta Pontificia y el Espacio Nacional Comprometido, op. cit. pp. 87-95.
} 
propuesta papal se perciben como una fuente de presión sobre la decisión del Gobierno argentino, capaces de crear una división en la opinión pública argentina. Otra dimensión que debe tenerse en cuenta es la que configura la acción concertada por la paz que promueven las jerarquías católicas de ambos países ${ }^{47}$, que en cierta medịda implicaría la convicción de que el peligro básico (conflicto arruado), no ha sido superado. Esta dimensión interna ofrece un ángulo complejo para el examen de las percepciones y, puede sostenerse la hipótesis de que el entendimiento a través de la vía religiosa está relacionado con la búsqueda de un consenso básico para situar el conflicto dentro de una acción pacificadora en el conjunto del sistema regional y universal.

Dentro de este cuadro, el ex Canciller argentino Miguel Angel Zavala Ortiz, propone modificar la actitud en beneficio de un pronunciamiento definitivo dentro del marco general de la mediación ${ }^{48}$, acentuando como objetivo "fundamental, preferente", la paz, tal como distintos gobiernos argentinos (conservadores, radicales, peronistas, militares, civiles) la han sostenido. Este enfoque, que no es aislado ${ }^{49}$, se sustenta en una percepción básicamente distinta acerca de lo que debe ser el entendimiento con Chile, situándolo dentro de una perspectiva más amplia, de inserción de Argentina en América Latina, para acercarla a los centros de decisión mundialso.

Situando estos planteamientos en el cuadro de la mediación desde que se da a conocer la propuesta papal, (diciembre de 1980), las percepciones que operaran en Argentina aparecen como múltiples, en especial por los cambios en la cúpula gobernante ${ }^{51}$, y se observa una creciente tendencia a insertar la mediación dentro de un contexto más general, dándole explícitamente una significación más amplia. Se puede definir esta actitud como inténtos para inclinar el curso de la mediación conforme a iniciativas argentinas. La reorientación de las negociaciones que busca el Canciller Camilión en septiembre de 1981, si bien tiene por objeto un acuerdo general

${ }^{*}$ Convocatoria conjunta a un día de acción por la paz, 8. 6. 1980; Congresos Mariano y Eucarísticos en Argentina y Chile, en 1980, etc. Un interesante análisis de este aspecto en Ignacio Pérez del Viso, "La Mediación Papal". I y Ir, Revista del Centro de Investigación y Acción Social, Buenos Aires, No 301, 1981, reproducida en El Mercurio, Santiago, 1982, 28. 5. 1982, pp. 12-13.

ts"Un Ambiente Preocupado y Preocupante", La Nacion, Buenos Aires, 3. 2. 1981, pp. 8-9. Zavala Ortiz reitera estos conceptos a fines de 1981 en Criterio, No 1973-74, diciembre, 1981, reproducidos en Hoy, Santiago, No 267, 18 7/11. 1982, pp. 19-24.

"Bonifacio del Carril, "La Mediación Papal; las Islas y el Mar", La Nación, Buenos Aires, 12. 2. 1981, p. 9.

${ }^{60} \mathrm{En}$ un sentido semejante, $M$. Arauz-Castex. "Habla el abogado de Isabel Perón", Qué Pasa, Santiago, 1982, № 596, p. 45.

EIEn marzo de 1981 asume el Gobierno, el General Roberto Viola y designa Canciller al diplomático Oscar Camilión. En diciembre de 1981, asume el General Leopoldo Galtieri $y$ designa Canciller a Nicanor Costa Méndez. 
con Chile en el Atlántico Sur, en lo que respecta a la mediación misma, la percepción dominante es de que a 30 meses de iniciado el proceso con el Vaticano, la solución está muy lejos de ser alcan$\mathrm{zada}^{52}$.

En todo caso, en la etapa de la mediación creemos que, si tiene algún sentido recurrir a interpretaciones por la vía de las percepciones, éstas deben además incorporar la dimensión de la relación de las partes con el mediador a partir del recurso a sus servicios en 1979 para que el Papa actúe como guía para un acercamiento.

La exhortación conjunta de los episcopados de Chile y de Argentina (3.5. 1980) al celebrarse el primer aniversario del inicio de los trabajos de la mediación, constituye una pieza importante para analizar la situación político-religiosa de la actuación papal, planteando la tesis de que "mediacion y paz se presentan así, en las circunstancias concretas de nuestros países, como dos elementos estrechamente vinculados entre sí"53. Elementos semejantes se encuentran en el discurso papal que acompañó la entrega de la propuesta papal a los dos países (12. 12. 1980) ${ }^{54}$. Una perspectiva similar adoptan declaraciones y manifestaciones de intelectuales y académicos argentinos y chilenos bajo la forma de exhortaciones a los gobiernos (mayo y diciembre de 1980) entre otras ${ }^{55}$. Esta dimensión tiene además una importante connotación interna, en particular dentro de Argentina, donde se plantean críticas a su respecto.

Desde el punto de vista de la relación entre ambos países y su actitud frente al proceso de mediación, la percepción chilena en el sentido de que el proceso se caracteriza por un estancamiento, derivado esencialmente de una actitud argentina hostil en general al entendipmiento (influencia de la concepción geo-estratégica) acompañada de una constante presión bélica $y$, de que existen sectores en Argentina interesados en llevar a cabo una política exterior paralela y de frenar cualquier arreglo mediante la divulgación de trascendidos.

Esto a su vez implica una dilación en la respuesta, actitud en la cual se proyecta una gran diversidad de opiniones sobre el tema. Estas percepciones se basan en gran medida, en las propias declaraciones oficiales $y$ en comentarios de fuentes vinculadas al Gobierno, que permiten presumir la inexistencia de una voluntad para definir términos de entendimiento con ${ }^{\prime} C h i l e^{56} \mathrm{y}$, la posibilidad de hacer una consulta popular en la materia.

${ }^{62}$ J. Iglesias Rouco, La Prensa, Buenos Aires, 7. 11. 1981.

${ }^{\infty}$ El Mercurio, Santiago, 4. 5. 1981, p. Al.

${ }^{5} \mathrm{~L}$ Osservatore Romano. 21. 12, 1980, pp. 7-9.

${ }^{60} L^{\prime}$ Osservatore Romano. 1. 6. 1980, p. 19 y El Mercurio, Santiago, 22. 12. 80.

"Ver Rodrigo Diaz Albónico, "Buena Fe y Mediación". El Mercurio, Santiago, 27. 11. 1981, p. A2. También "Balance de la Mediación", Ibíd, 31 12. 1981, página A.3. 
La deliberación en el sistema argentino sería, además lenta; en ella primaría el ejercicio de análisis que dificulta la decisión (Comité Militar, Presidente, Ganciller), lo que a su vez no contribuiría a facilitar una decisión clara acerca de posiciones y actitudes que mostrar al otro país. Si se analiza el período que va desde la presentación de la propuesta papal hasta fines de marzo de 1981, el 14 de diciembre, Iglesias Rouco ${ }^{57}$, afirma que "el Gobierno argentino dará una respuesta afirmativa a la propuesta del Papa". Días más tarde se reúne el Comité Militar, compuesto por las tres ramas de las Fuerzas Armadas y se comienza a reiterar los trascendidos en el sentido que el Gobierno hará precisiones, lo que finalmente sucede el 25 de marzo. En ese lapso de tiempo, se publica un mapa interpretativo de la propuesta, con un comentario que señala que los colaboradores del Vaticano han impuesto su tesis en el sentido de que Argentina posee más recursos humanos y territoriales que Chile y que, por lo tanto es la nación que debe hacer mayores sacrificios.

En torno a las contradictorias opiniones que se vierten en este período $^{58}$, y que refleja la prensa argentina ${ }^{59}$, las percepciones se orientan a desarrollar algunas hipótesis relativas al rol que el Vaticano está dispuesto a jugar para obtener una definición y por ende la adhesión argentina a su propuesta, así como, a si Argentina se mantendrá o no dentro del campo de la mediación. Estas hipótesis no varían en todo el curso de 1981, observándose además una reiteración del ciclo diplomático y de tensión militar (Argentina cierra sus fronteras terrestres con Chile en abril de 1981), lo que reintroduce la mediación como un elemento activo para la distensión.

En este caso particular, el ámbito interno argentino se percibe como más fluido y, en forma bastante directa se plantea qué sectores de ese Gobierno estarían señalando que en un cuadro caracterizado por la dureza militar (tanto antisubversivas como de defensa de las fronteras nacionales), difícilmente podría ensayarse desde dentro un proyecto de apertura política ${ }^{60}$. Aunque no es una apreciación generalizada, desde el punto de vista del conflicto y del desarrollo de la mediación, ella proporciona elementos de juicio para corroborar imágenes pre-existentes en cuanto faltaría una real voluntad de negociar ${ }^{61}$. Al mismo tiempo, esta situación ha permitido suponer que existe una relación entre la mantención de la inestabi-

${ }^{5}$ La Prensa, Buenos Aires.

${ }^{\circ} \mathrm{Se}$ sugiere que la Diplomacia argentina estaría actuando sobre la base de tres premisas: I) no puede haber guerra; 2) la propuesta papal de diciembre de 1980 no puede ser aceptada tal como se redactó y, 3) la mediación no puede fracasar. La Nación, Buenos Aires, 3. 10. 1981.

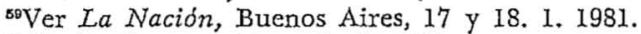

${ }^{\infty}$ Clarin, Buenos Aires, 3. 5. 1981.

ar "Viaje del Canciller Argentino", El Mercurio, Santiago, 10, 9. 1981, p. A3. 
lidad gubernamental en Argentina y las características que la mediación ha ido adquiriendo y tiene a mediano y largo plazo ${ }^{62}$.

Esta perspectiva reorienta nuestra apreciación de las percepciones básicas en el conflicto $y$, sin tener en cuenta el asunto de las Malvinas (a partir de abril de 1982), puede postularse que ésas tienden a reiterar las que se desarrollaron en la etapa previa a la mediación, en función más bien de la relación de armonía o tensión y no de la búsqueda de un tratado definitivo ${ }^{63}$.

Un componente importante de esta reiteración está dada por la imagen dominante en Chile en el sentido de que la falta de posiciones jurídicas claras favorables a las tesis argentinas, son un factor coadyuvante para que ese país tenga una actitud de semicompromiso con el proceso de mediación. Al cabo de un año de haberse formulado la propuesta papal, el siguiente comentario ilustra este punto: "La experiencia de todo un año de espera de la respuesta argentina lleva a la conclusión de que la propuesta del mediador no es del agrado del Gobierno argentino, y que busca por todos los medios modificar sus términos de manera de satisfacer sus aspiraciones territoriales, lo que, tal como están planteadas las cosas debería ser a costa de Chile" 64 .

Esta percepción está vinculada igualmente a otra según la cual la posición argentina (nuevo Gobierno encabezado por el General Galtieri, que conserva el cargo de Gomandante en Jefe del Ejército) no variaria en 1982 fundamentalmente $y$, de que denunciaria el Tratado sobre solución judicial de controversias, de 1972. Argentina lo hace en enero de 1982. Iglesias Rouco señala, por otra parte, a fines de diciembre de $1981^{65}$, que Estados Unidos, interesado en mantener el statu quo en la zona austral, había comprendido que la resistencia de grupos domésticos era cada día mayor frente a la propuesta papal y que esto obligaría al Gobierno de Galtieri a ser prudente.

Se reducen así las hipótesis acerca de lo que los paises pueden hacer en el corto plazo a pocas opciones. Dentro de ellas surge nuevamente el recurso judicial conforme al Tratado de 1972 vigente después de la prórroga de septiembre de 1982, como una alternativa

'22El jefe de la delegación argentina ante la mediación, General (R) Ricardo Etcheverry Boneo, en octubre de 1981, coincidía con esta opinión, cable UPr, El Mercurio, Santiago, 31. 10. 1981. Asimismo, Somos, Buenos Aires, 31. 10. 1981, citando a una alta fuente militar indica que "el problema del Beagle no se va a arreglar en este Gobierno, ni tampoco en el próximo".

"Dentro de un maxco jurídico, el análisis de la falta de buena fe en el comportamiento argentino, se inserta dentro de las tendencias de este periodo. Ver nota 55 supra.

a" "Argentina y la Mediación", El Mercurio, Santiago, 10. 12. 1981, p. A3.

"La Prensa, Buenos Aires, 27. 12. 1981. 
inmediata en caso de fracaso de la mediación y, la necesidad de lograr un acuerdo de amistad y solución de controversias.

\section{Desarrollos recientes}

Los planteamientos en juego, por otra parte están influenciados por imágenes subyacentes, unas de las cuales percibe el arbitraje (antes de la mediación papal) y la mediación misma, como alternativas a la soberanía nacional, cuando los resultados de la utilización de esos mecanismos ya han sido conocidos ${ }^{63}$. Esto envuelve un alto grado de hostilidad en la apreciación de los resultados no sólo en el conjunto de argumentos que se dan para rechazar la sentencia arbitral de $1977^{6 \tau}$, sino también ante la posibilidad de que Ghile decida utilizar el recurso a la Gorte Internacional de Justicia, en 1981 y 1982, conforme al Tratado sobre solución judicial vigente desde 1972. $\mathrm{Pa}$ rece ajena a esta percepción, la idea de que pudiese existir alguna presión o interés internacional sobre Argentina, a fin de mantener a este país dentro de la mediación.

Vinculado a este punto, pero dentro de un marco de referencia distinto, cabe considerar la existencia de percepciones que tengan en cuenta el interés o actitudes de otros gobiernos acerca de la evolución de las relaciones chileno-argentinas, del proceso de la mediación y del conflicto en sí mismo. Un elemento que aparece con alguna constancia en análisis chilenos es precisamente el alcance de las relaciones argentino-soviéticas y sus repercusiones en el área ${ }^{68} \mathrm{da}-$ da la mayor presencia soviética, aunque no aparezcan directamente ligadas al conflicto mismo.

Es particularmente frecuente que en medios chilenos se sitúe el conflicto dentro de un contexto más amplio, configurado por las relaciones en el Cono Sur y de la región 69 .

A este respecto, cabe agregar algunas variaciones de esta situa-

\footnotetext{
"Del Viso, analiza este punto dentro de lo que denomina un "horizonte de referencia". Op. cit., Vol. II, p. 5.

orNicanor Costa Méndez, "La Argentina, Chile y Gran Bretaña en el Atlántico Sur". Declaración a La Nación, reproducidas en El Mercurio, Santiago, 20. 7. 1977, p. A3.

ag"Argentina tiene una serie de problemas, como la venta de sus granos, el problema nuclear, asf como su amistad con la uRss obedece a la búsqueda de una mayor libertad política de movimiento. En todo este tipo de conversaciones políticas algo hay que ceder siempre. Aquí, lo que está cediendo Argentina es la mayor participación de la uRss en su área. Eso de pasada nos afecta a nosotros y a todos los pafses". Declaraciones del Comandante en Jefe de la Escuadra, Vicealmirante Ronald McIntyre, El Mercurio, Santiago, 27. 4. 1980. En igual sentido, considerable atención se ha prestado al desenvolvimiento de la cooperación argentino-soviética en materia nuclear, intercambio comercial, asistencia técnica y financiera en el proyecto hidroeléctrico del Paraná Medio, acuerdos de pesca y de investigación, etc.

ca"Dilatada Respuesta", El Mercurio, Santiago, 13. 8. 1981.
} 
ción a raíz del conflicto anglo-argentino de las Malvinas, en 1982. Juegan varias interpretaciones en este punto $y$, no necesariamente contradictorias.

Una de ellas, percibe a Chile como un complemento de la estrategia británica y "seguramente usufructuario en alguna medida de la política inglesa en el Atlántico Sur" y su proyección hasta la Antártica ${ }^{70}$. Conforme con la otra, que opera más en el corto plazo, la decisión de ocupar las islas Malvinas el 2 de abril, que adopta el Gobierno del General Galtieri, obedeció a dos razones básicas: "la sensación de un creciente cerco geopolítico; segundo, la evidencia de un aislamiento político interno"'r1. En cuanto a los factores geopolíticos, ese país no habría obtenido satisfacción de dos negociaciones cruciales, en el conflicto del Beagle con Chile y sobre las Malvinas con Gran Bretaña. En este punto se encuentran las dos percepciones ya que en el largo y en el corto plazo se cree que si la Argentina se quedase sin Beagle y sin Malvinas vería "cerrado" su acceso al Sur e interrumpido, por falta de un punto de apoyo terrestre en línea directa su proyección hacia más de un millón de kilómetros cuadrados del Continente antártico.

De alguna manera Argentina necesita entonces reforzar sus derechos en el Atlántico Sur para impedir lo que aparece como un "movimiento de pinzas" chileno-británico, países ambos con pretensión antártica ${ }^{72}$.

Los nuevos enfoques, y ajustes a las percepciones preexistentes también se presentan en análisis chilenos, a la luz del conflicto de las Malvinas, con un mayor acento en los aspectos prescriptivos, vale decir, lo que es deseable que la Diplomacia chilena tenga en cuenta para conducir la relación con Argentina y con los países del hemisferio ${ }^{73}$. En gran medida, los análisis se basan en que los intereses y derechos en el conflicto del Beagle estén vinculados a la suerte de la crisis malvinense, asi como a las opciones estratégicas y políticas que adopte el Gobierno argentino.

Sin duda que el conflicto de las Malvinas ha situado el rol de

\footnotetext{
${ }^{70}$ Osiris Villegas, La Propuesta Pontificia y el Espacio Nacional Gomprometido, op. cit., p. 73.

TMariano Grondona, "La Guerra de las Malvinas: un intento de comprensión", Separata de $A$ Fondo, Buenos Aires, octubre, No 23, p. 4.

${ }^{72}$ Ibid, pp. 4-5. El tema ha sido objeto de especulaciones en Argentina hasta el punto que J. Iglesias Rouco ha insinuado que el Gobierno del General Pinochet estaría buscando una guerra relámpago en la Patagonia, con apoyo británico. "A la Deriva", La Prensa, Buenos Aires, 26. 10. 1982, p. 1. La tesis ha sido duramente criticada en Chile. Ver "Acusaciones Insólitas", El Mercurio, Santiago, 31. 10. 1982, p. A3.

${ }^{72}$ Ver en especial, "Después de las Falklands-Malvinas. Saldos y Oportunidades del Conflicto del Atlántico Sur", Economia y sociedad, Santiago, 1982, No 4, pp. 7-9 y, "Chile Después del Conflicto Anglo-Argentin.", Realidadx Santiago, 1982, pp. 8-8.
} 
las percepciones en un cuadro más amplio y complejo, y desde el punto de vista interno argentino, es importante considerar los efectos que para el desarrollo de la relación con Chile tienen los intentos de construir un consenso político mínimo que sustentar a la Diplomacia de ese país. ¿Corresponde esencialmente el conflicto de] Beagle al ciclo militar?74. En todo caso, una de las perspectivas nuevas que se estaría configurando a raíz de la guerra de las. Malvinas y sus efectos en el conflicto austral, sería el de la latinoame ricanización de los intereses argentinos y la revalorización del entendimiento con Chile, así como con los demás países de la región ${ }^{75}$. La solidez de esta aspiración está aún en etapa de prueba, así como sus repercusiones en la mediación. El modelo democrático que ha propiciado la Multipartidaria (febrero 1982) argentina, como alternativa al régimen actual, invoca el principio de la separación oceánica como básico en la política exterior de ese país ${ }^{76}$.

Esto no implica necesariamente una nueva percepción en el tema, pero sugiere la hipótesis de si el mismo planteamiento formulado por actores diferentes ofrece perspectivas reorientadoras dentro de lo que ha sido la posición oficial.

\section{GONSTDERAGIONES FINALES}

Este trabajo plantea sólo algunas posibilidades que el recurso de las percepciones ofrece como medio para interpretar actitudes y orientaciones. No constituye un análisis exhaustivo, puesto que no tiene en cuenta en su totalidad al intercambio oficial entre los paises, sino que ciertas interpretaciones básicas.

Por otra parte, del tema mismo surgen algunas limitaciones intrínsecas, principalmente derivadas de que procesalmente no se trata de un conflicto terminado, aunque tal como lo señaláramos al comienzo, la perspectiva de lo que es el conflicto varía según las definiciones que se le atribuyan.

Interesante resulta, sin duda, utilizar el marco teórico de las percepciones en una situación que es concebida fundamentalmente dentro de los estudios geopolíticos, con enfoques parciales y bastante teóricos. El contraste entre una teoría que tiende a privilegiar el rol personal, con una selección de percepciones propias, moldeadas sobre la base de la propia experiencia, con la del pensamiento geopolítico, que acentúa las variables del medio ambiente internacional y el valor del espacio, para la nación, ha resultado sin em-

${ }^{74} \mathrm{La}$ expresión es del ex Canciller argentino Oscar Camilión, "Anacronismo Histórico", Jornal do Brasil, São Paulo, 1. 4. 1982.

"T"Tesis desarrollada por Mariano Grondona, "Adiós a las armas", Visión, 23.

7. 1982, p. 27.

T0Propuesta (Buenos Aires: El Cid Edit., 1982), p 157. 
bargo un ejercicio útil para entender el conflicto e indispensable para entender las orientaciones de los diversos planteamientos.

Por otra parte, vale la pena señalar que las hipótesis que plantea la percepción geopolíticamente orientada, tienden a basarse en algunos elementos constantes: conocimiento histórico, sentimiento colectivo (de frustración o satisfacción), imágenes estables, tanto acerca del propio país como de su vinculación con el mundo exterior. A pesar de que en general, presentan un aspecto hostil respecto del propio sistema interno, en el caso de Argentina, crítica a Ia Diplomacia, etc., han sido constantemente utilizadas para guiar actitudes en el conflicto. Estas actitudes y planteamientos han sido valoradas negativamente por las percepciones chilenas.

Por último, pareciera difícil insertar los diferentes episodios y decisiones individuales dentro de un marco conceptual que tenga en cuenta sólo las percepciones de los actores o de las explicaciones principales, ya que no se alcanza a configurar con precisión las alternativas que los mismos actores plantean en las decisiones de corto, mediano y largo plazo $y$, el marco tiende a ser más prescriptivo que cognitivo de la realidad. 